\title{
A construção do conceito de número através da Literatura Infantil, de acordo com as proposições da BNCC
}

The construction of number concept through Children's Literature according to the propositions of the BNCC

La construcción del concepto del número a través de la Literatura Infantil, de acuerdo con las proposiciones de la BNCC

Recebido: 15/07/2021 | Revisado: 22/07/2021 | Aceito: 23/07/2021 | Publicado: 31/07/2021

\author{
Aline Vieira da Cunha \\ ORCID: https://orcid.org/0000-0002-3392-4942 \\ Instituto Federal de Educação, Ciência e Tecnologia Sul-rio-grandense \\ E-mail: alinepacto@gmail.com \\ Rafael Montoito \\ ORCID: https://orcid.org/0000-0002-3294-3711 \\ Instituto Federal de Educação, Ciência e Tecnologia Sul-rio-grandense \\ E-mail: xmontoito@gmail.com
}

\begin{abstract}
Resumo
Este artigo foi elaborado a partir de uma dissertação defendida cuja pesquisa, desenvolvida com abordagem qualitativa e bibliográfica/documental, apresentou possibilidades de se identificar, nos contos clássicos, os processos mentais que a criança elabora para a construção do número. Assumindo, portanto, uma relação possível entre a literatura infantil e a matemática, em que a primeira apresenta potencialidades pedagógicas para o ensino da segunda, este texto tem como objetivo discutir a possibilidade de desenvolver, através dos contos clássicos, as orientações da Base Nacional Comum Curricular - BNCC - em relação à construção do número na Educação Infantil. Para atingir tal objetivo, o artigo foi dividido em três partes: na primeira são apontadas algumas contribuições da literatura para o ensino da matemática; na segunda, o texto discorre sobre como se dá o processo de construção do número e, na terceira parte, são apresentadas algumas sugestões de atividades, a partir dos clássicos infantis, para desenvolver as orientações da BNCC, como forma de elucidar as discussões. As atividades propostas foram elaboradas a partir do conto "O Pequeno Polegar" como forma de exemplificar possibilidades pedagógicas e de estimular o olhar do professor que pretende ensinar matemática a partir dos contos clássicos. De acordo com as análises e discussões apresentadas, é possível concluir que a literatura favorece a aprendizagem da matemática, uma vez que cria contextos de aprendizagem, despertando o interesse e a imaginação, favorecendo a comunicação e proporcionando o desenvolvimento tanto da língua materna, quanto da linguagem matemática.
\end{abstract}

Palavras-chave: Literatura e matemática; Processos mentais; Construção do número; Matemática da educação infantil; Construção do número na BNCC.

\begin{abstract}
This article was elaborated from a dissertation defended whose research, developed with a qualitative and bibliographic/documentary approach, presented possibilities of identifying, in the classic tales, the mental processes that the child elaborates for the construction of the number. Therefore, becoming a possible relationship between children's literature and mathematics, in which the first represents pedagogical potentialities for the teaching of the second one, this article aims to discuss the possibility of developing, through classic tales, the guidelines of the Curriculum Common National Base - BNCC - regarding to the construction of the number in kindergarten stage. In order to achieve this goal, the article was divided into three parts: in the first one, some contributions of literature to the teaching of Mathematics are pointed out; in the second, the text discusses how the process of number construction happens and, in the third part, some suggestions of activities are presented, based on children's classics, to develop the guidelines of the BNCC, as a way to elucidate the discussions. The proposed activities were developed from the story "The Little Thumb" to exemplify pedagogical possibilities and to stimulate the view of the teacher who intends to teach Mathematics using the classic tales. According to the analyses and discussions presented, it is possible to conclude that literature favors the Mathematics learning, since it creates learning contexts, awakening interest and imagination, stimulating communication and providing the development of both mother tongue and mathematical language.
\end{abstract}

Keywords: Literature and mathematics; Mental processes; Number construction; Mathematics of early childhood education; Number construction in the BNCC. 


\begin{abstract}
Resumen
Este artículo fue elaborado a partir de una disertación defendida cuya la investigación, desarrollada con un abordaje cualitativa y bibliográfica/documental, presentó posibilidades de identificarse, en los cuentos clásicos, los procesos mentales que los niños elaboran para la construcción del número. Asumiendo, por lo tanto, una relación posible entre la literatura infantil y matemáticas, en que la primera presenta potencialidades pedagógicas para la enseñanza de la segunda, este texto tiene como objetivo discutir la posibilidad de desarrollar, a través de los cuentos clásicos, las directrices de la Base Nacional Común Curricular - BNCC - en relación a la construcción del número en la Educación Infantil. Para lograr este objetivo, el artículo fue dividido en tres partes: en la primera son señaladas algunas contribuciones de la literatura para la enseñanza de matemáticas; en la segunda, el texto discurre sobre cómo funciona el proceso de la construcción del número y, en la tercera parte, son presentadas algunas sugerencias de actividades, a partir de los clásicos infantiles, para desarrollar las directrices de la BNCC, como forma de aclarar las discusiones. Las actividades propuestas fueran elaboradas a partir del cuento "Pulgarcito" como forma de ejemplificar posibilidades pedagógicas y de estimular la mirada del profesor que pretende enseñar matemáticas a partir de los cuentos clásicos. De acuerdo con las análisis y discusiones presentadas, es posible concluir que la literatura favorece el aprendizaje de la matemática, una vez que cría contextos de aprendizaje, despertando el interés y la imaginación, favoreciendo la comunicación y proporcionando el desarrollo tanto de lengua materna, cuanto del lenguaje matemático.
\end{abstract}

Palabras clave: Literatura y matemáticas; Procesos mentales; Construcción del número; Matemáticas en la educación infantil; Construcción del número en la BNCC.

\title{
1. Introdução: orientações da BNCC
}

O presente texto parte, de um modo global, das discussões, estudos e pesquisas realizadas no GENEP - Grupo de Estudo em Narrativas e Educação na Pós-modernidade -, o qual é formado por pesquisadores do Instituto Federal de Educação, Ciência e Tecnologia Sul-rio-grandense (IFSUL - Pelotas, RS) e por mestrandos e doutorandos do programa de pós-graduação desta instituição. De modo mais específico, ele é estimulado pelos resultados apresentados na dissertação da primeira autora deste artigo, os quais aqui são retomados, revisitados e aprofundados considerando-se, agora, um olhar atento e atualizado à Base Nacional Comum Curricular (BNCC).

A intenção deste artigo é discutir a possibilidade de se desenvolver, através dos contos clássicos, as orientações da BNCC em relação à construção do número na Educação Infantil. Para tanto, partiu-se da seguinte indagação: como desenvolver os objetivos de aprendizagem e desenvolvimento propostos pela BNCC, referentes à construção do número na Educação Infantil, através dos contos clássicos? Tal questão se faz bastante pertinente se considerarmos que momentos de contação de histórias são comuns nas aulas de Educação Infantil, as quais fomentam discussões e aprendizagens de diversos assuntos que vão desde conteúdos escolares até hábitos, valores e comportamentos.

Para responder a essa questão, partiu-se de uma análise das orientações da BNCC referentes à Educação Infantil. Este seguimento não se organiza por disciplinas, como os demais, mas sim por Campos de experiências, dentro dos quais são definidos os objetivos de aprendizagem e desenvolvimento. São cinco esses campos da experiência: (1) O eu, o outro e o nós, que trata da interação com os pares e com os adultos; (2) Corpo, gestos e movimentos, que trata do desenvolvimento e conhecimento do próprio corpo; (3) Traços, sons, cores e formas, que trata das diferentes manifestações artísticas, culturais e científicas; (4) Escuta, fala, pensamento e imaginação, que trata do desenvolvimento da linguagem e da comunicação; (5) Espaços, tempos, quantidades, relações e transformações, que trata dos diversos espaços, tempos e conhecimentos matemáticos. É importante ressaltar que esses campos não são propostos de maneira hierárquica ou continuada, isto é, não se espera que um campo seja "esgotado" em sala de aula para, depois, se passar a outro; a maneira de desenvolvê-los dirá respeito às escolhas pedagógicas do regente da classe e/ou da coordenação pedagógica da escola, sempre visando privilegiar os direitos de aprendizagem e desenvolvimento na educação infantil, contemplados nos verbos conviver, brincar, participar, explorar, expressar e conhecer-se (Brasil, 2018).

Embora em mais de um desses campos seja possível se desenvolver noções de conteúdos e aprendizagens matemáticas, para este artigo buscou-se identificar, no campo de experiência Espaços, tempos, quantidades, relações e 
transformações, os objetivos de aprendizagem e desenvolvimento relacionados aos processos de construção do número.

De acordo com o documento, no campo da experiência Espaços, tempos, quantidades, relações e transformações, dentre outros conhecimentos,

as crianças também se deparam, frequentemente, com conhecimentos matemáticos (contagem, ordenação, relações entre quantidades, dimensões, medidas, comparação de pesos e de comprimentos, avaliação de distâncias, reconhecimento de formas geométricas, conhecimento e reconhecimento de numerais cardinais e ordinais etc.) que igualmente aguçam a curiosidade. Portanto, a Educação Infantil precisa promover experiências nas quais as crianças possam fazer observações, manipular objetos, investigar e explorar seu entorno, levantar hipóteses e consultar fontes de informação para buscar respostas às suas curiosidades e indagações (Brasil, 2018, p. 43).

A partir de uma análise deste campo da experiência, foram selecionados os objetivos referentes ao foco de estudo deste artigo - construção do número - e, a seguir, buscou-se nos contos clássicos identificar quais histórias possibilitavam o desenvolvimento de tais objetivos.

A Educação Infantil é a primeira etapa da Educação Básica, sendo fundamental para todo o processo educacional. O documento da BNCC aponta como eixo estruturante das práticas pedagógicas, de acordo com as DCNEI - Diretrizes Curriculares Nacionais da Educação Infantil - as interações e a brincadeira, "experiências nas quais as crianças podem construir e apropriar-se de conhecimentos por meio de suas ações e interações com seus pares e com os adultos, o que possibilita aprendizagens, desenvolvimento e socialização" (Brasil, 2018, p. 37).

$\mathrm{O}$ documento ressalta, ainda, a necessidade de se ter intencionalidade educativa nas práticas pedagógicas, o que significa dizer que o professor necessita organizar e propor atividades e experiências que permitam às crianças desenvolverem conhecimentos sobre si mesmas, sobre os outros e sobre a natureza. Para tanto, o educador deve lançar mão de uma pluralidade de materiais e situações que permitam à criança explorar materiais diversos, brincar, interagir com outras pessoas e aproximar-

se da literatura. É justamente essa relação que a criança pode estabelecer com a Literatura Infantil que interessa para a discussão deste texto.

\section{Metodologia}

Buscamos complementar os resultados da dissertação da primeira autora deste artigo, retomando sua pesquisa, porém agora dando destaque às intencionalidades e indicações da BNCC. Tanto a dissertação quanto a composição deste artigo embasam-se em metodologias de pesquisa qualitativa, pois entendem como "importante a interpretação por parte do pesquisador com suas opiniões sobre o fenômeno em estudo" (Pereira et al., 2018, p. 67). Com isso, assumimos uma postura que considera que

Os pesquisadores que adotam a abordagem qualitativa em pesquisas se opõem ao pressuposto que defende um modelo único de pesquisa para todas as ciências, baseado no modelo de estudo das ciências da natureza. Estes pesquisadores se recusam a legitimar seus conhecimentos por processos quantificáveis que venham a se transformar em leis e explicações gerais. Afirmam que as ciências sociais têm sua especificidade, que pressupõe uma metodologia própria. Os pesquisadores qualitativistas recusam o modelo positivista aplicado ao estudo da vida social (Goldenberg, 2004, p. 16-17).

Sendo assim, a partir da elaboração de uma pergunta exploratória que traduzisse nossa inquietação enquanto pesquisadores (Bortoni-Ricardo, 2008), organizamos a execução da pesquisa dividindo-a em três partes. Objetivando responder à questão norteadora desta pesquisa - como desenvolver os objetivos de aprendizagem e desenvolvimento propostos pela BNCC, referentes à construção do número na Educação Infantil, através dos contos clássicos? -, procedemos como detalhado a seguir, executando a metodologia desta pesquisa em três partes: 
(1) inicialmente fizemos uma análise das orientações da BNCC referente à Educação Infantil e identificamos o campo da experiência e os objetivos de aprendizagem e desenvolvimento referentes ao foco de estudo deste artigo. Nesta parte, consideramos uma abordagem documental, que "é aquela realizada a partir de documentos, contemporâneos ou retrospectivos, considerados cientificamente autênticos (não-fraudados); tem sido largamente utilizada nas ciências sociais" (Gerhardt \& Silveira, 2009, p. 69).

(2) buscamos, nos contos clássicos, identificar as histórias que possibilitavam um trabalho voltado para desenvolver os objetivos de aprendizagem. Neste ponto, a ênfase dada foi a da pesquisa bibliográfica, pois entendemos que os livros dos clássicos infantis são documentos (fontes) construídos socialmente e com intencionalidades. Os livros compõem "uma modalidade específica de documentos, que são obras escritas, impressas em editoras, comercializadas em livrarias e classificas em bibliotecas" (Gerhardt \& Silveira, 2009) - em particular, as escolares.

(3) considerando os estudos dos passos anteriores, e cotejando trechos das histórias infantis com os enunciados dos objetivos de aprendizagem expressos na BNCC, elaboramos propostas - que são, também, interpretações - que os põem em diálogo. Trata-se, aqui, de um exercício pedagógico interpretativo, que tensiona nossos saberes pedagógicos prévios para produzir um conhecimento novo, a partir de elementos novos, na perspectiva da elaboração de problemas para o ensino de Matemática (Gontijo et al., 2019).

Entretanto, ressaltamos que os passos (1), (2) e (3) não foram executados de maneira independente, mas favorecendo análises que se auto complementavam, às vezes de maneira cíclica ou repetida, de modo que "transitamos" na composição e conexão entre estas partes, a fim de produzir as interpretações apresentadas neste texto.

\section{Literatura e matemática: uma impregnação mútua}

A aproximação com a Literatura Infantil pode produzir diversas situações de aprendizagens que proporcionam tanto a interação com outras crianças, como o desenvolvimento de brincadeiras e a aprendizagem de conteúdos. Isso acontece porque, de acordo com Amarilha (2004), a literatura exerce um verdadeiro fascínio - não só sobre as crianças, mas principalmente nelas - que pode e deve ser aproveitado para despertar o interesse e proporcionar aprendizagens mais significativas. A Literatura proporciona um envolvimento emocional com a narrativa e possibilita, ao aluno, viver o jogo ficcional, mobilizando, assim, sua atenção e interesse (Campos \& Montoito, 2010), o que é fundamental para qualquer aprendizagem.

Outro aspecto importante para a aprendizagem matemática, potencializado pela literatura, é a imaginação, pois essa é fundamental para que a criança adentre ao jogo ficcional e viva, ainda que temporariamente, no imaginário. O processo imaginativo desencadeado ao ler ou ouvir histórias auxilia não só na compreensão da leitura e do enredo ficcional, mas também no desenvolvimento da criatividade, da capacidade de compreender outros pontos de vista e está presente no processo de planejamento, elaboração e criação de projetos (Maria, 2009); vale ressaltar que, ao longo dos anos escolares, as ações de planejar, elaborar e criar são postas a serviço de diferentes disciplinas, inclusive da matemática, as quais ganharam mais destaque nas competências gerais e específicas da matemática, apontadas na BNCC (Brasil, 2018). Daí pressupormos que estabelecer diálogos entre a literatura e a matemática, já nos anos iniciais, pode influenciar positivamente nos modos de o aluno aprender e se relacionar com a matemática em toda sua trajetória acadêmica (Montoito, 2019).

A imaginação está presente não só na construção do conceito de número, mas também na compreensão das operações, na resolução de problemas, dentre outros conceitos matemáticos. Tanto números, quanto operações são representações de ideias e conceitos, podendo ser tomados como representação da realidade (Machado, 2011) e, portanto, favorecer o desenvolvimento da imaginação torna-se imprescindível.

Ao utilizar-se da Literatura Infantil para o ensino da matemática, outro aspecto é amplamente favorecido: a capacidade de comunicação. Essa, de acordo com Lorenzato (2011), é uma etapa fundamental na aprendizagem matemática. 
Segundo o autor, a criança deve ir da ação no concreto à representação desta ação, sendo a comunicação uma etapa importante nesse processo, razão pela qual Lorenzato (2011) pontua que a criança deve ser estimulada em três momentos distintos: relatar o que está fazendo, durante a ação; em seguida, contar o que fez sem executar a ação; e, posteriormente, deve ser incentivada a registrar o que fez. Esse registro inicialmente é iconográfico, evoluindo para a representação simbólica até chegar ao uso de símbolos matemáticos. Neste sentido, a ilustração de uma história infantil pode auxiliar o professor no ensino, desempenhando um papel importante não só na comunicação dos acontecimentos da narrativa, com a representação dos fatos, mas também na etapa do registro, uma vez que serve de apoio tanto para a criança que está na etapa do registro iconográfico como para aquela que já se utiliza de símbolos matemáticos para fazer seu registro.

Por isso é importante o professor, ao ler histórias, direcionar o olhar das crianças para as ilustrações, instigando-as a buscar, nas imagens, pistas que as ajudem a decifrar o código ficcional. Neste sentido, Farias (2013, p. 59) ressalta a necessidade de desenvolver

um trabalho minucioso com as crianças, apontando ou levando-as a descobrir esses elementos técnicos que fazem progredir a ação ou que explicam espaço, tempo, características das personagens etc. [o que] aprofundará a leitura da imagem e da narrativa e estará, ao mesmo tempo, desenvolvendo a capacidade de observação, análise, comparação, classificação, levantamento de hipóteses, síntese e raciocínio (FARIAS, 2013, p. 59).

Todas as habilidades listadas na citação anterior são fundamentais para qualquer aprendizagem. Além disso, a Literatura proporciona, para a criança, um alargamento de seu domínio linguístico, o que é fundamental no processo comunicativo. Amarilha (2013, p.17) aponta que as histórias "ampliam seu universo de ideias e conhecimentos, e favorecem o desenvolvimento da linguagem, da imaginação, da observação, da memória, da reflexão e da capacidade de atenção dos estudantes." Todas estas são habilidades fundamentais para qualquer aprendizagem, sendo a linguagem, para Zilberman (2003), o mediador entre a criança e o mundo, motivo pelo qual um trabalho que favoreça a ampliação do domínio linguístico da criança pode vir, ainda que em longo prazo, proporcionar que esta tenha uma maior percepção e compreensão de mundo. Reforçando essas ideias, Smole, Cândido e Stancanelli (1995, p. 13) apontam que "através da conexão entre literatura e matemática, o professor pode criar situações na sala de aula que encorajem os alunos a compreenderem e se familiarizarem mais com a linguagem matemática, estabelecendo ligações cognitivas entre a linguagem materna, conceitos da vida real e a linguagem matemática."

A linguagem matemática, para Machado (2011), é um sistema de representação da realidade e, por isso, sua aprendizagem é essencial para o desenvolvimento da capacidade de interpretar, analisar, sintetizar, conceber, significar e projetar. Porém, a matemática não possui uma oralidade própria e, sendo assim, para que ocorra uma comunicação por via oral, é necessário estabelecer uma relação de complementaridade com a língua materna: uma impregnação mútua.

Deste modo, a língua materna desempenha um papel fundamental na aprendizagem matemática pois, para além da compreensão de enunciados, é essencial na construção de conceitos, na elaboração da comunicação e no desenvolvimento e compreensão da linguagem matemática. O autor ainda ressalta que "é preciso compreender a Matemática como um sistema básico de expressão e compreensão de mundo, em sintonia e em absoluta complementaridade com a língua materna. Em outras palavras, é preciso reencantar a Matemática, e para tanto, a exploração de sua aproximação visceral com língua materna é fundamental (Machado, 2011, p. 181).”

Neste sentido, a inter-relação entre a literatura e a matemática mostra-se um terreno fértil pois, como vimos, a literatura desempenha papel fundamental no desenvolvimento da linguagem, uma vez que amplia o domínio linguístico do leitor, dando a este "o que" e o "como" dizer (Maria, 2009), além de possibilitar desvelamentos da matemática, trazendo à toda aspectos seus que pouco aparecem nos currículos escolares (D’Amore, 2012). Desta forma, explorar esta inter-relação parece 
apropriado, como sugerem Souza e Carneiro (2015, p. 398):

conectar literatura infantil e matemática possibilita a criação de situações de ensino que permitem explorar as relações entre língua materna e matemática; propicia circunstâncias que mostram ao aluno a importância e a utilidade da linguagem e o simbolismo matemático, bem como o uso apropriado desses símbolos e da terminologia matemática; e permite também o desenvolvimento da comunicação matemática, podendo levar o aluno a compreender conteúdos matemáticos e a linguagem matemática.

A aprendizagem matemática desenvolvida a partir da literatura infantil pode ser explorada não só durante a leitura como após a contação da história, uma vez que a narrativa ficcional proporciona a criação de diversos contextos de aprendizagens, tornando o aprender mais significativo e prazeroso. Contudo, embora esteja sendo defendido neste artigo o uso da literatura para o ensino da matemática, este contato da criança com o livro deve ser preservado como um momento absolutamente prazeroso e instigante (Arnold, 2016). Por isso, o fio condutor da narrativa não dever ser interrompido e qualquer questionamento, durante a contação, dever ser no sentido de despertar a curiosidade, a imaginação e a antecipação do que está por vir, favorecendo a comunicação e a argumentação.

\section{A Construção do Conceito de Número}

De acordo com Oliveira e Silva (2015, p. 313), "a construção do conceito de número não pode ser ensinada diretamente, pois a criança precisa ir gradativamente construindo-a por si mesma". Para que isso ocorra, é necessário que esta vivencie diferentes situações de aprendizagem em que necessite estabelecer as mais diversas relações pois, de acordo com Kamii (2007), a criança irá progredir na construção do conhecimento lógico-matemático conforme desenvolve sua capacidade de estabelecer relações e comparar objetos de diferentes formas, o que se dá na interação com o meio em que vive.

A criança irá consolidar o conceito de número quando for capaz de coordenar diversas ações sobre os objetos (Nogueira, 2011). A essas ações, Lorenzato (2011) denomina-as como "processos mentais básicos para a aprendizagem matemática", ressaltando que estes são constitutivos das estruturas cognitivas que acompanharão o indivíduo por toda a vida. São eles: correspondência, comparação, classificação, sequenciação, seriação, inclusão, conservação, entre outras.

Estes processos mentais, embora possam ser analisados em separado, tem seu desenvolvimento de forma interrelacionada, de acordo Lorenzato (2011), interpondo-se e integrando-se, de modo que um vai esclarecendo o outro, o que torna o ensino da matemática mais complexo. O autor enumera ainda, algumas variáveis, do campo conceitual de número, que precisam ser consideradas para a organização do ensino deste:

correspondência um a um; cardinalidade de um conjunto; ordinalidade na contagem; contagem seriada um a um; contagem por agrupamentos; composição e decomposição de quantidades; reconhecimento de símbolos numéricos; reconhecimento de símbolos operacionais; representação numérica; operacionalização numérica; percepção de semelhanças; percepção de diferenças; percepção de inclusão; percepção de invariância (Lorenzato, 2011, p. 31 - 32).

É possível perceber que o desenvolvimento do conceito de número exige, para além do reconhecimento de numerais, que seja ofertado à criança diversas situações em que necessite refletir, comparar, relacionar, incluir etc. Dito de outro modo, é importante que a criança estabeleça as mais diversas formas de relação entre os objetos, atentando às ressalvas de Lorenzato (2011, p. 33) de que "é nesse entremeado de diferentes noções que se dá a construção do conceito de número, construção essa que não é linear, se o fosse, seu ensino seria facilitado".

Neste sentido, o professor pode encontrar na literatura infantil uma importante aliada, pois esta, além de fomentar a imaginação e a criatividade, ampliar o domínio linguístico e favorecer a comunicação, suscita, de forma espontânea, a elaboração das mais diversas relações, além de criar contextos de aprendizagem que podem proporcionar um aprender mais 
significativo e prazeroso, conforme mostram diversas pesquisas anteriores (Montoito et al., 2021; Arnold \&Dalcin, 2020; Gonçalves \& Pozzobon, 2019; Maia \& Maranhão, 2015; Colins et al., 2016) - essas, contudo, sem considerarem as orientações da BNCC, as quais têm importância capital na elaboração deste texto.

\section{Desenvolvendo as Orientações da BNCC a partir dos Contos Clássicos}

Existem muitos livros de literatura infantil desenvolvidos especificamente para o ensino da matemática. Contudo, como o intuito deste artigo é, também, instrumentalizar o professor para trabalhar com os materiais que já possui na escola ou que sejam de fácil acesso, optamos por analisar os contos clássicos, uma vez que estes são amplamente encontrados tanto nas bibliotecas escolares (Arnold, 2016) quanto nas livrarias, além de serem estes, de acordo com Machado (2009, p. 80), um "precioso acervo de experiências emocionais, de contatos com vidas diferentes e de reiteração da confiança em si mesmo" que proporcionam, ainda segundo a autora, vivências simbólicas de conflitos psicológicos de grande impacto na mente infantil, possibilitando que estas saiam dessa experiência mais felizes.

Por conseguinte, o professor que pretende usar essas histórias com o intuito de ensinar conteúdos escolares, não só os de matemática, deve atentar para a qualidade literária e estética da obra, pois estas, por terem sua origem na tradição oral, sofreram muitas alterações, seja pela intenção de tornar essas histórias em leitura de iniciação, resultando em textos vazios estética e artisticamente, ou com a intenção de extirpar as marcas de violência, negando emoções primitivas. Em ambos os casos, a história perde seu impacto psicológico, pois a criança não é confrontada com tais emoções e perde a oportunidade de aprender a lidar com elas de forma simbólica. Para Bettelheim (2017), para que a história exerça tal impacto é necessário que esta seja, antes de tudo, uma obra de arte.

As coleções utilizadas para a análise apresentada na dissertação da primeira autora deste artigo e revisitadas para a composição deste texto foram duas, ambas da Editora Maurício de Souza: Clássicos Ilustrados e Clássicos para Sempre. Estas coleções foram escolhidas pelas características de suas narrativas (tanto a verbal quanto a visual) que apresentam histórias não muito resumidas, preservando sua qualidade literária, embora em algumas histórias seja observada a remoção de algumas marcas de violência. A narrativa visual merece grande destaque pela sua qualidade, não só estética, mas também pela relação de absoluta complementaridade que estabelece com a narrativa verbal, sendo as ilustrações apresentadas que muitas vezes possibilitam a exploração do conto para o ensino da matemática (Cunha, 2019).

Analisando as orientações da BNCC em relação ao ensino de matemática na educação infantil, o campo de experiências Espaços, tempos, quantidades, relações e transformações apresenta oito objetivos de aprendizagem e desenvolvimento referente à faixa etária crianças pequenas (4 anos a 5 anos e 11 meses). Dentre estes, para a discussão que aqui apresentamos, foram selecionados os objetivos referentes à construção do conceito de número:

- EI03ET01 ${ }^{1}$ - Estabelecer relações de comparação entre objetos, observando suas propriedades.

- EI03ET04 - Registrar observações, manipulações e medidas, usando múltiplas linguagens (desenho, registro por números ou escrita espontânea), em diferentes suportes.

- EI03ET05 - Classificar objetos e figuras de acordo com suas semelhanças e diferenças.

- EI03ET07 - Relacionar números às suas respectivas quantidades e identificar o antes, o depois e o entre em uma sequência. (Brasil, 2018, p. 51 - 52)

Vale-se ressaltar que estes objetivos de aprendizagem são bastante amplos, ou seja, não dizem respeito exclusivamente à aprendizagem dos números (por exemplo: para se comparar objetos, podem ser consideradas suas formas ou

${ }^{1}$ Os códigos da BNCC são construídos seguindo uma sequência lógica: as duas primeiras letras (EI) indicam a etapa da Educação Infantil; os dois primeiros dígitos (03) indicam o grupo por faixa etária ( neste caso, Crianças Pequenas de 4 anos a 5 ano e 11 meses); as letras subsequentes (ET) indicam o campo de experiência (Espaços, tempos, quantidades, relações e transformações) e o último par de números (01) diz respeito à posição da habilidade na numeração sequencial dentro do campo e experiência. 
tamanhos; para se registrar observações, podem ser usados desenhos que atestem as diferenças ou semelhanças entre o que foi observado etc). Entretanto, neste artigo específico, nossa intenção é pensar estes objetivos associados aos processos mentais da construção do número que, a partir das atividades apresentadas adiante, mostraremos que os contemplam.

Sendo assim, a literatura infantil, enquanto disparador conectivo (Farias, 2006), oferece potencialidades de trabalho ao professor, para que este pense e planeje atividades pedagógicas visando satisfazer estes objetivos no campo da construção do número.Com estas questões em mente, buscamos, na análise dos contos clássicos, realizada por Cunha (2019) e expressa no Quadro 1,as histórias que apresentam elementos matemáticos que possibilitam elaborar estratégias de ensino que visem desenvolver estes objetivos.

Quadro 1 - Processos mentais encontrados nos Clássicos Infantis.

\begin{tabular}{|c|c|c|c|c|c|c|c|c|}
\hline \multicolumn{9}{|c|}{ Processos mentais encontrados nos Clássicos Infantis } \\
\hline Clássicos Infantis & 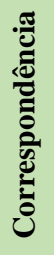 & 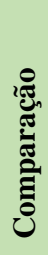 & 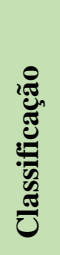 & 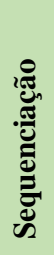 & & 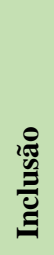 & 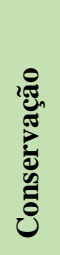 & 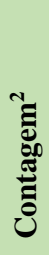 \\
\hline Cachinhos Dourados & $\mathrm{x}$ & $\mathrm{x}$ & & & $\mathrm{x}$ & & & \\
\hline Branca de Neve & $\mathrm{x}$ & $\mathrm{x}$ & $\mathrm{x}$ & & & & $\mathrm{x}$ & $\mathrm{x}$ \\
\hline Três Porquinhos & $\mathrm{x}$ & & & & & & & $\mathrm{x}$ \\
\hline Pinóquio & & $\mathrm{x}$ & & & $\mathrm{x}$ & & & \\
\hline O Pequeno Polegar & $\mathrm{x}$ & $\mathrm{x}$ & $\mathrm{x}$ & & & $\mathrm{x}$ & $\mathrm{x}$ & $\mathrm{x}$ \\
\hline Soldadinho de Chumbo & & & $\mathrm{x}$ & & & $\mathrm{x}$ & & \\
\hline As 12 Princesas Dançarinas & $\mathrm{x}$ & & $\mathrm{x}$ & & & & $\mathrm{x}$ & $\mathrm{x}$ \\
\hline O patinho Feio & & & $\mathrm{x}$ & & & $\mathrm{x}$ & & $\mathrm{x}$ \\
\hline
\end{tabular}

Fonte: Cunha (2019).

Neste quadro é possível observar as histórias que possibilitam um trabalho voltado para desenvolver os processos mentais necessários à construção do conceito de número. Dentre elas, a história "O Pequeno Polegar" (Souza, 2016) foi selecionada para comentar algumas estratégias de ensino, como forma de exemplificar possíveis inter-relações entre literatura e matemática, tendo em vista as orientações da BNCC e os objetivos de aprendizagem destacados anteriormente.

Antes mesmo de começar a contar a história, o professor pode mostrar para as crianças a imagem a seguir e questionar qual o motivo de o menino ser chamado de Pequeno Polegar. 
Figura 1: Ilustração do livro O Pequeno Polegar.

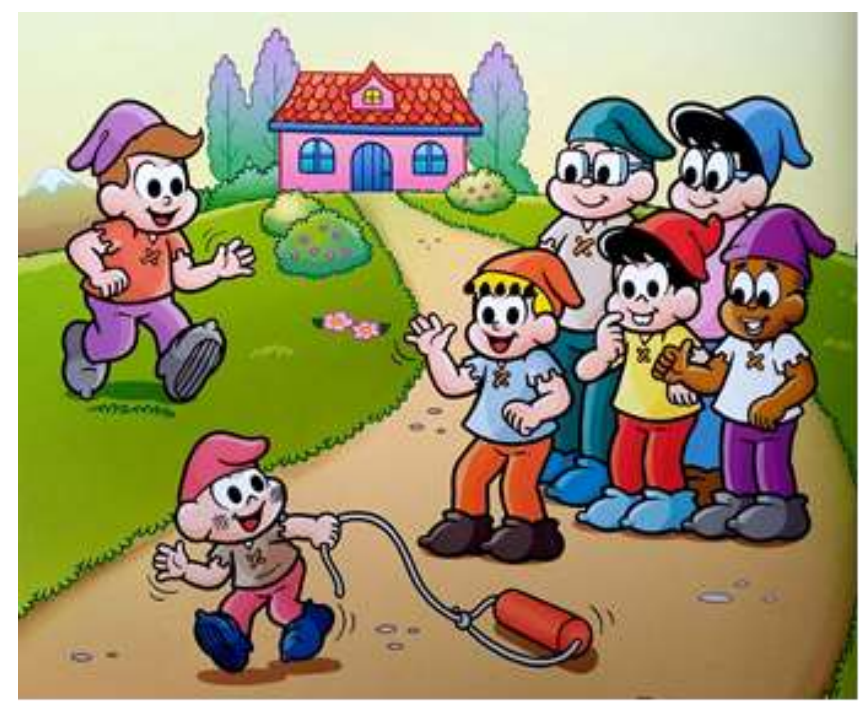

Fonte: Souza (2016, p. 02).

$\mathrm{Na}$ imagem aparecem crianças de diversos tamanhos, sendo que algumas aparentam ter tamanhos semelhantes. Para responder à questão proposta, a criança necessita estabelecer comparação de tamanho entre os personagens (EI03ET01). Após a contação da história, essa passagem pode ser retomada, pedindo-se às crianças que, comparando os personagens, digam qual é o maior, o menor e quais parecem ter a mesma altura. Posteriormente, é possível se estimular a comparação (EI03ET01) de tamanho das crianças entre si, buscando organizar a turma numa série do menor ao maior (EI03ET01 e EI03ET07), ou ao inverso. As crianças podem registrar suas alturas com marcações em um cartaz na parede (EI03ET04), que serve para comparação futura do quanto cresceram ao longo do ano. A professora pode também entregar fitas ou cordões com a medida de sua altura e estimular que compare os tamanhos das fitas ou cordões (EI03ET01) para saberem quem é maior, quem é menor ou quem tem a mesma altura.

É possível, também, separar a turma em pequenos grupos, com no mínimo 3 alunos e no máximo 4, e, a partir da comparação das fitas com suas medidas, organizar uma série por ordem de tamanho e distribuir números, de 1 a 4 , de acordo com a série organizada, desenvolvendo o aspecto ordinal do número (EI03ET07). Outra opção é chamar a atenção das crianças para a sequência numérica e para a posição dos números, questionando quem vem antes do 2, quem vem depois, quem está entre o 1 e o 3 e etc (EI03ET07). Ainda, pode-se embaralhar os grupos e pedir que cada criança se coloque no seu grupo de acordo com a ordem numérica do seu número. Nestas atividades, estão sendo explorados os objetivos EI03ET01, EI03ET04 e EI03ET07. Para ressaltar o caráter imbricado dos campos da experiência, podemos ressaltar que, embora não seja o foco da análise apresentada neste artigo, as atividades acima descritas possibilitam explorar, além dos processos da construção do número, outros objetivos dos campos $\mathrm{O}$ eu, e outro e o nós e Corpo, gestos e movimentos.

Outra passagem que pode ser retomada após a contação da história é a representada na ilustração a seguir, a partir da qual se pode questionar as crianças sobre quantas pessoas (personagens) estão na imagem, quantas são adultas e quantas são crianças, quantos usam óculos e quantos não usam, quantos tem azul na roupa e quantos não tem, dentre outras comparações (EI03ET01, EI03ET05 e EI03ET07). 
Figura 2: Ilustração do livro O Pequeno Polegar.

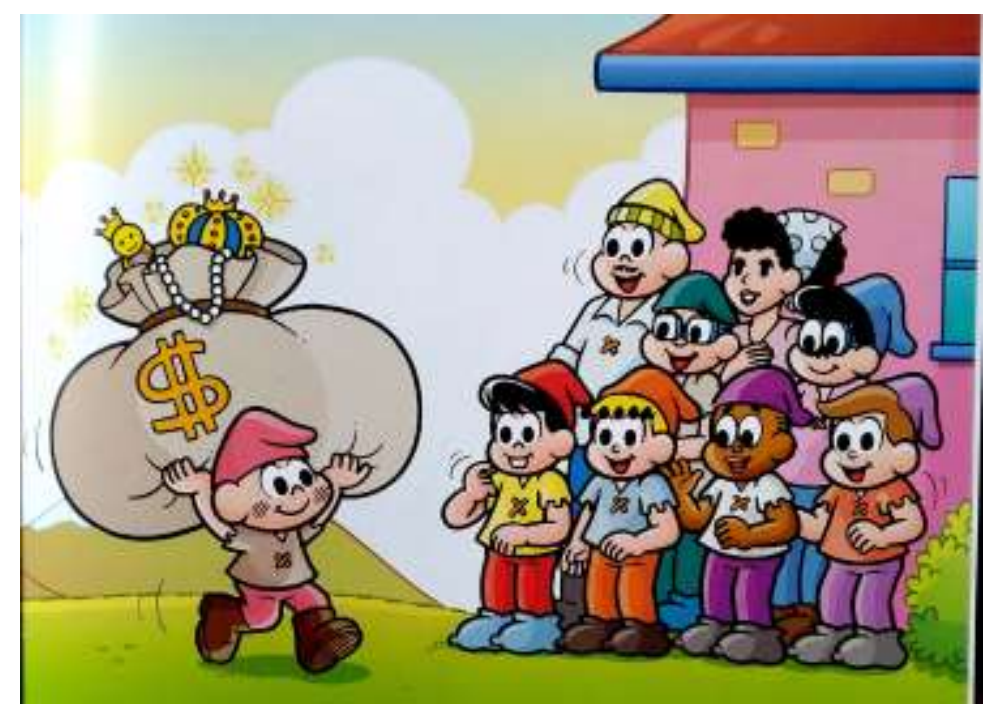

Fonte: Souza (2016, p. 15).

$\mathrm{Na}$ imagem, pode-se observar que cada personagem possui características muito diferentes das dos demais e algumas semelhanças. O importante é aguçar a atenção das crianças para estas características, suscitando diversas comparações (EI03ET01) e classificações (EI03ET05). Esta atividade pode ser registrada de diferentes formas (EI03ET04): de acordo com o nível da criança, o registro pode ser pictográfico (com desenho dos personagens), iconográfico (com símbolos representando as unidades) ou simbólico (com símbolos convencionais como números), conforme aponta Lorenzato (2011).

Em seguida, pode-se questionar as crianças sobre suas características próprias, tais como cor e comprimento do cabelo, uso de óculos, cor dos olhos, cores das roupas, estilo de sapato etc. (EI03ET01). A partir disso, brincando com música, pode-se pedir que, quando ela parar, agrupem-se conforme as características que a professora disser (EI03ET05): crianças com cabelo comprido e com cabelo curto, quem tem azul na roupa e quem não tem, quem usa óculos e quem não usa etc. Após a brincadeira, as crianças podem registrar com desenho (EI03ET04) quais colegas apresentam semelhança a ela de acordo com a classificação determinada pela professora. Estas atividades exploram todos os objetivos destacados e, além disso, possibilitam trabalhar com outros campos da experiência, tais como: $\mathrm{O}$ eu, o outro e o nós; Corpo, gestos e movimentos; Traços, sons, cores e formas.

Em muitas passagens da história não aparecem todos os personagens nas ilustrações, como as que vemos a seguir. Essas imagens podem ser aproveitadas para levar as crianças a compararem quantidades logicamente (EI03ET01 e EI03ET07). Lembremos que, nesta faixa etária, a contagem, para muitas crianças, ainda não é precisa e, por isso, para descobrir em qual imagem tem mais personagens, ao invés da contagem, elas podem se utilizar da distribuição espacial ou da correspondência um a um dos personagens. Por isso é importante estar atento às estratégias utilizadas pelas crianças. 
Figura 3: Ilustração do livro O Pequeno Polegar.

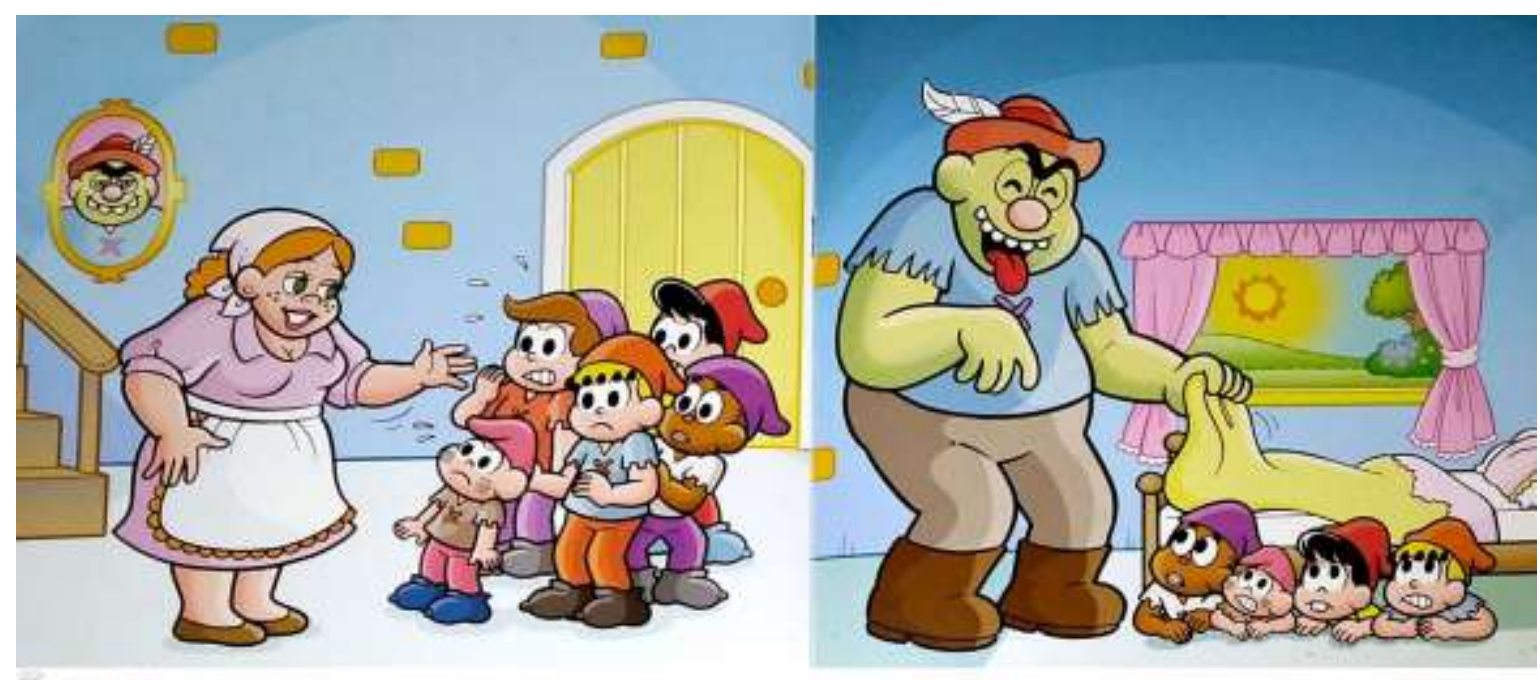

Fonte: Souza (2016, p. 08 e 09).

Nas imagens aparecem agrupamentos com quantidades diferentes de crianças, pois nem todas estão presentes. Utilizando-se das imagens em que aparecem diferentes agrupamentos dos personagens (como a ilustração 01 e a 03), pode-se pedir que comparem as figuras (EI03ET01) e descubram quantos (EI03ET07) e quais personagens estão escondidos na página 09, por exemplo. Ao serem estimuladas a comparar dois conjuntos, as crianças têm a possibilidade de intuir a adição e a subtração, fundamentais para o processo de desenvolvimento da conservação de quantidade (Cunha\& Montoito, 2021). É possível ainda, utilizando estas ilustrações, pedir que relacionem o numeral ao conjunto com quantidade correspondente (EI03ET07) e, posteriormente, que organizem os grupos do que tem mais para o que tem menos (EI03ET01 e EI03ET05).

Como nesta faixa etária as crianças necessitam, também, vivenciar atividades mais dinâmicas, é possível distribuir ilustrações com diferentes agrupamentos e pedir para que a criança, junto com os colegas, forme um grupo com igual quantidade à da ilustração (EI03ET07). Depois de os grupos estarem formados, questionar qual tem mais crianças, qual tem menos e se algum tem a mesma a quantidade (EI03ET01). É importante observar qual estratégia as crianças utilizam para chegar à resposta dada. Pode-se ainda pedir que cada grupo busque o número correspondente à quantidade de elementos do seu grupo (EI03ET07), expressos em fichas previamente dispostas com os numerais e, depois, ao som de uma música, dançar com seu grupo; quando parar a música, devem executar uma ação pedida pela professora, por exemplo: ficar de um lado da sala os grupos com menos de 5 e, do outro lado, os com mais de 5 (repetir a brincadeira com outros numerais). Após a atividade, podem desenhar o seu grupo (EI03ET04), representando a quantidade (EI03ET07) tanto com o desenho de seus elementos como com o numeral correspondente. Estas atividades trabalham todos os objetivos selecionados. Assim como nas atividades anteriores, outros campos da experiência são contemplados nestas brincadeiras.

Estas são apenas algumas sugestões de atividades, podendo o professor, com um olhar atento para as histórias, elaborar outras que desenvolvam os objetivos de aprendizagem e desenvolvimento propostos pela BNCC, não somente referente ao campo da experiência que foi objeto desta análise, mas também a todos os demais campos da experiência. É preciso ainda pontuar que atividades semelhantes podem ser desenvolvidas a partir de outros contos, pois as crianças necessitam vivenciar diversas situações, repetidamente, em que possam refletir e estabelecer diferentes relações entre os objetos. Só assim, irão, aos poucos, progredir na construção do conceito de número (Cunha \& Montoito, 2021). 


\section{Considerações Finais}

Tendo em vista a questão norteadora desta discussão - como desenvolver os objetivos de aprendizagem $e$ desenvolvimento propostos pela BNCC, referentes à construção do número na Educação Infantil, através dos contos clássicos?-, podemos afirmar que a matemática presente nos contos pode ser explorada durante a contação da história com questionamentos que agucem a atenção e a curiosidade das crianças, levando-as a desenvolverem raciocínios que favoreçam a aprendizagem matemática, porém, vale lembrar que estes questionamentos não devem interromper o fio condutor da narrativa.

A história, também, pode ser explorada após a contação, retomando passagens do conto ou ilustrações que favoreçam tais raciocínios. As ilustrações permitem a criação de diversas atividades que potencializam o desenvolvimento das orientações da BNCC. Existe, ainda, a possibilidade de o conto ser utilizado para a criação de contextos de aprendizagem com os quais pode-se propor atividades que visem o ensino de conceitos matemáticos (como por exemplo na atividade sugerida a partir da ilustração 01, na qual as crianças são incentivadas a fazer comparação de tamanhos entre si).

Um aspecto importante na escolha dos livros a serem utilizados com o intuito de auxiliar no ensino de matemática é a qualidade da ilustração pois, muitas vezes, são estas que fornecem elementos necessários para elaboração de atividades e ajudam a despertar raciocínios necessários para a aprendizagem matemática. Por isso, o professor que pretende se utilizar da literatura para o ensino da matemática necessita avaliar não só a qualidade da narrativa, mas também a qualidade das ilustrações e como estas se inter-relacionam com a narrativa verbal.

De acordo com o exposto, é possível afirmar que literatura favorece o desenvolvimento da imaginação, fundamental no processo de aprendizagem, e amplia o domínio linguístico, desenvolvendo a comunicação e a capacidade argumentativa, além de familiarizar a criança com a linguagem matemática. Sendo assim, uma proposta pedagógica que se utilize destas interrelações entre literatura e matemática pode gerar aprendizagens mais fecundas, uma vez que desperta o interesse, mobiliza o aluno para aprender e propicia interações entre as crianças de forma lúdica, proporcionando uma aprendizagem mais significativa e prazerosa (Cunha \& Montoito, 2020).

Para concluir, cabe lembrarmos que, neste artigo foi escolhido um campo de conhecimento e alguns objetivos de conhecimentos aos quais se deu destaque, dirigindo-se uma atenção mais focada nos processos mentais para a construção do número - porém, a ideia central desta discussão pode ser extrapolada para outros campos e objetivos de conhecimento e para distintos saberes matemáticos, possibilitando outras discussões e gerando novos estudos que relacionem literatura infantil, aprendizagem matemática e orientações da BNCC.

\section{Referências}

Amarilha, M. (2004). Estão mortas as fadas? Literatura infantil e prática pedagógica. (6a ed.), Editora Vozes.

Amarilha, M. (2013) Alice que não foi ao país das maravilhas: educar para ler ficção na escola. Livraria da Física.

Arnold, D. S. (2016). Matemáticas presentes em livros de leitura: Possibilidades para a Educação Infantil (Dissertação de mestrado). Mestrado Profissional em Ensino de Matemática - Instituto de Matemática, Universidade Federal do Rio Grande do Sul.

Arnold, D. S., \&Dalcin, A. (2020). Matemática e literatura infantil: um livro, um jogo e o "desafio" de desenhar o tempo. Revista internacional de pesquisa em Educação Matemática.10(2), 167-181.

Bettelheim, B. (2017). A Psicanálise dos Contos de Fadas. (34a ed.), Paz e Terra.

Brasil. (2018). Ministério da Educação. Base Nacional Comum Curricular. Brasília.

Bortoni-Ricardo, S. M. (2008). O professor pesquisador: introdução à pesquisa qualitativa. Parábola Editorial.

Campos, R. S. P.\& Montoito, R. (2010) O texto alternativo ao livro didático como proposta interdisciplinar do ensino de ciências e matemática. In: PIROLA, N. A. (org.). Ensino de ciências e matemática, IV: temas de investigação. Cultura acadêmica, 4, 157 - 174.

Colins, F., Machado Jr, A. G. \& Gonçalves, T. O. (2016). Alfabetização matemática e literatura infantil: possibilidades para uma prática pedagógica integrada. Amazônia: revista de educação em ciências e matemática. 13(25), 75-84. 
Cunha, A. V. da. (2019). Guardados do baú da vovó: sobre matemática, contação e histórias e a construção do conceito de número. 2019. Dissertação (Programa de Pós-graduação em Educação) - Mestrado Profissional em Educação e Tecnologia, Instituto Federal de Educação, Ciência e Tecnologia Sul-riograndense, Pelotas.

Cunha, A. V. da \& Montoito, R. (2020). Uma revisão sobre pesquisas brasileiras que investigam as inter-relações entre literatura infantil e matemática. Research, societyanddevelopment. 9(9), e462997496.

Cunha, A. V. da\& Montoito, R. (2021). Baú da Vovó: Processos mentais para a aprendizagem do conceito de número. CRV.

D’Amore, B. (2012). Matemática, estupefação e poesia. Editora Livraria da Física.

Farias, C. A. (2006). Alfabetos da alma: histórias da tradição na escola. Sulina.

Farias, M. A. (2013). Como usar a Literatura infantil na Sala de Aula. Contexto.

Gerhardt, T. E. \& Silveira, D. T. (2009). (Orgs.). Métodos de pesquisa. Editora da UFRGS.

Goldenberg, M. (2004). A arte de pesquisar: como fazer pesquisa qualitativa em ciências sociais. Record.

Gonçalves, C. P. P. \&Pozzobon, M. C. C. (2019). A literatura infantil e as matemáticas: contextos das histórias e grandezas e medidas. Práxis educacional. 15(36), 398-414.

Gontijo C. H., Carvalho, A. T., Fonseca, M. G. \& Farias, M. P. (2019). Criatividade em matemática: conceitos, metodologias e avaliação. Editora Universidade de Brasília.

Kamii, C. (2007). A criança e o número: implicações educacionais da teoria de Piaget para a atuação com escolares de 4 a 6 anos. (35a ed.), Papirus.

Lorenzato, S. (2011). Educação Infantil e percepção matemática. Campinas. Autores Associados LTDA.

Maia, M. G. B. \& Maranhão, C. (2015). Alfabetização e letramento em língua materna e em matemática. Ciência \& educação. 21(4), 931-943.

Machado, A. M. (2009). Como e por que ler os clássicos universais desde cedo. Objetiva.

Machado, N. J. (2011). Matemática e língua materna: análise de uma impregnação mútua. Cortez.

Maria, L. de. (2009). O clube do livro. Ser leitor - que diferença faz? Globo.

Montoito, R. (2019). Entrelugares: pequeno inventário inventado sobre matemática e literatura. Bolema, 33(64), 892-915.

Montoito, R., Cunha, A. V. \& Weissheimer, R. F. (2021). Criando e ressignificando histórias infantis para o ensino de matemática nos anos iniciais: relatos de pesquisas. In: Navarro, E. R., \& Souza, M. C. Educação matemática em pesquisa: perspectivas e tendências. Científica Digital.

Nogueira, C. M. I. (2011). Pesquisas atuais sobre a construção do conceito de número: para além de Piaget? Educar em Revista, 1/2011, 109-124.

Oliveira, K. B. A.\&Silva, A. C. (2015). Construção do conceito de número: uma análise de atividades matemáticas desenvolvidas pelo Subprojeto PIBID/UFMT/CUR nas escolas de ensino fundamenta de Rondonópolis. Revista Eventos Pedagógicos: Articulação universidade e escola nas ações do ensino de matemática e ciências, 6. (02), $311-327$.

Pereira, A. S., Shitsuka, D. M. Parreira, F. J., \& Shitsuka, R. (2018). Metodologia da pesquisa científica. UFSM. https://www.ufsm.br/app/uploads/sites/35 8/2019/02/Metodologia-da-Pesquisa-Cientifica_final.pdf.

Souza, M. de. (2016). O Pequeno Polegar. Coleção Clássicos Ilustrados. Maurício de Souza: Girassol Brasil.

Smole, K. S., Cândido, P. T. \& Stancanelli, R. (1997). Matemática e literatura infantil. (2a ed.), Lê, 1997.

Souza, A. P. G. de\& Carneiro, R. F. (2015). Um ensaio teórico sobre literatura infantil e matemática: práticas de sala de aula. Educação Matemática e Pesquisa. 17(02), $392-418$.

Zilberman, R. (2003). A literatura infantil na escola. Global. 